Conference Paper

\title{
Review of low aspect ratio blade dynamics for electrical axial fans and compressors
}

Roque, J.P.C., Bolam, R.C., Vagapov, Y., Monir, S. and Anuchin, A.

This is a paper presented at the 56th IEEE Int. Universities Power Engineering Conference UPEC2021, Middlesbrough, UK, 31 Aug. - 3 Sept. 2021

Copyright of the author(s). Reproduced here with their permission and the permission of the conference organisers.

\section{Recommended citation:}

Roque, J.P.C., Bolam, R.C., Vagapov, Y., Monir, S. and Anuchin, A. (2021), 'Review of low aspect ratio blade dynamics for electrical axial fans and compressors.' In: Proc. 56th IEEE Int. Universities Power Engineering Conference UPEC-2021, Middlesbrough, UK, 31 Aug. - 3 Sept. 2021, pp. 1-6, doi: 10.1109/UPEC50034.2021.9548223 


\section{Review of Low Aspect Ratio Blade Dynamics for Electrical Axial Fans and Compressors}

\author{
Jhon Paul C. Roque \\ Faculty of Art, Science and Technology \\ Glyndwr University \\ Wrexham, UK
}

\author{
Robert Cameron Bolam \\ Faculty of Art, Science and Technology \\ Glyndwr University \\ Wrexham, UK
}

\author{
Yuriy Vagapov \\ Faculty of Art, Science and Technology \\ Glyndwr University \\ Wrexham, UK
}

\author{
Shafiul Monir \\ Faculty of Art, Science and Technology \\ Glyndwr University \\ Wrexham, UK
}

\author{
Alecksey Anuchin \\ Department of Electric Drives \\ Moscow Power Engineering Institute \\ Moscow, Russia
}

\begin{abstract}
The quest for lighter and shorter propulsion systems has led to the reduction of axial compressor and fan blade chord-lengths. Theoretical and experimental results show that the geometrical aspect-ratio criterion significantly affects the overall performance of axial flow compressors and fans. In conducting this review, it was found that the experimental results differ from one literature source to another. Highlighting that the way in which blade aspect ratio affects the performance of axial flow compressors and fans is still not fully understood. Nonetheless, the reviewed literature has still proven valuable for compressor and fan design. This paper focuses on creating a review of the available literature relating to how low aspect ratio blades may affect the performance of electrical axial compressors and fans.
\end{abstract}

Keywords—axial compressor; fan; blade aspect ratio; electric propulsion

\section{INTRODUCTION}

Increasing concerns over the effects of climate change have accelerated the requirement to electrify transportation in order to reduce carbon dioxide emissions. Although various works of literature identify the agricultural industry as a prominent source of $\mathrm{CO}_{2}$ emissions, it is considered that any form of change in agricultural practices could take too long to have a significant impact. Therefore, as a more immediate response, the global community are looking towards the transportation and power generation industries to take more effective actions.

The first electric-powered flight took place in 1883, by two French aviators Albert-Charles Tissandier and Gaston Tissandier, when the brothers successfully attached a Siemens electric motor to the propeller of an airship. Unfortunately, rapid advancements in internal combustion engine technology overshadowed this marvellous achievement, leaving the field of electric propulsion almost unexplored [1]. Aircraft electrical propulsion was not the only technology that was almost forgotten. The first account of an axial compressor is a reversed turbine which, however, did not yield high efficiency. The combination of low efficiency and the better understood centrifugal compressor, with efficiencies ranging from $70-80 \%$, led to the abandonment of axial compressor development for many years. It wasn't until the development of the gas turbine engine took place, prior to and during the second world war that interest in the more efficient axial compressor design emerged. Nowadays, due to the advances in fluid mechanics, axial compressors can reach high efficiencies in the regions of $90 \%$ [2]

This work is funded by the Welsh Government (WEFO) under the SMARTExpertise initiative (Project Reference 82321) and is supported by the European Regional Development Fund.
Conventional axial compressor and fan configurations are hub-driven. The hub-driven configuration is convenient to manufacture, but its most significant advantage is its centralised drive shaft. This allows the fan or compressor to be powered by a single component hence reducing the overall weight of the device. However, propulsion for fast flight requires that electric fans or compressors achieve high power densities in order to maximise the transfer of energy to the airflow and multi-staging in order to optimise the thrust generated per frontal area and reduce the momentum drag of the propulsion device. Hub mounted motors introduce challenges when implementing more stages resulting in heavier and bulkier designs and problems routing the electric supply cables to the motor(s). Thus, ultimately limiting hub driven all-electric compressors and fans to lower speed flight applications with single or possibly dual-stage configurations.

The rim-driven configuration is not new as it has been in use for marine applications for many years. Unlike the conventional hub-driven configuration, as the name suggests, the power of a rim-driven configuration originates from the rim where the blades are attached. This has three main advantages over hub-driven devices. In a hub-driven configuration, the stress concentrates at the blade's base (root) as the centrifugal force tries to pull the blades off the hub. This means that the only supporting structure of the blade is the root. However, in a rim-driven configuration, the blades are supported at their root (hub) and their tip (rim), making the rim-driven configuration a two-point support structure. Furthermore, assuming that the blades weigh the same, the rim of a rim-driven fan and compressor would be under tension from the weight of the blades, transferring stresses away from the root. As the motor of the rim-driven fan and compressor is at the periphery of the rotodynamic parts, the electrical supply terminals for the motor are more easily accessible, thus simplifying production and manufacture. Ultimately, a rim-driven fan or compressor has the potential of multi-staging, independent rotor operation, and contra-rotation, making rim-driven configuration a more adaptive and flexible option for electrical propulsion. Rim driven architectures are favourable to low aspect ratio blade designs and offer the possibility of an optimum transferral of energy from the fan blades to the airflow.

This paper focuses on how electric axial compressors and electric fans may behave with low aspect ratio blades. The blade aspect ratio is the ratio of blade height to the chord length. It is noteworthy that the terms high and low aspect ratio indicate a criterion that differentiates the two. Current literature, available to the author on high and low aspect ratio blades, uses different high and low aspect ratio 
values. Hence, the high and low aspect ratio classification either does not exist or is inaccessible to the author. Nonetheless, the reviewed literature indicates that this geometrical criterion affects the overall performance of an axial compressor and fans through various forms of aerodynamic losses and phenomena.

In Section II, the paper pinned down the difference between a compressor and a fan, then later highlighted the distinctive characteristics between a rim-driven and hubdriven fan and compressor. Section III explores the effects and potential effects of electrifying the aviation industry. Section IV delved into how velocity diagrams could be used to analyse the isentropic efficiency, also known as adiabatic efficiency, and demonstrated the performance difference of a single-stage fan to a dual-stage contra-rotating fan. Section V discussed De Haller number and diffusion factor usage at different design stages and diffusion factor limits. Then section VI mentioned two essential design criteria used during compressor and fan design. Section VII discern the difference between a stall and a surge while discussing their nature, and then in section IIX, the effects of blade aspect ratio are discussed in detail. Finally, section IX presents the key findings of this review.

\section{BACKGROUND}

The visible difference between rim-driven and hubdriven fans and compressors is the mounting of the blades. For hub-driven fans or compressors, the blades are mounted at the hub and often have a tip clearance, but on rim-driven fans and compressors, designers can mount the blades at the rim or the rim and the hub, and they always have no tip clearance; one may use the term "shrouded blade" to describe a rim-driven fan or compressor blade as the blades are attached to the shroud. The authors would like to clarify that these visible differences are at the surface level and are weak descriptions because the distinguishable characteristic of rim-driven and hub-driven fans and compressors is the origin of the mechanical energy that drives the blades. In a hub-driven fan or compressor, the mechanical energy originates at the hub, powering the blades by the blade's root then energising the working fluid. On a rim-driven fan or compressor, the mechanical energy originates at the rim, powering the blades by the blade's tip then energising the working fluid.

\section{ElECtrificAtion OF THE AviATION INDUSTRY}

The electrification of aircraft propulsion has many advantages beyond the scope of environmental issues. Electrifying aircraft propulsion will have a significant economic impact as it will need new infrastructures, devices, and crew to maintain it. Overall, this will generate large scale new employment opportunities. Our behaviour as we travel will also change. As happened when we transitioned from horse and carriage to automobile and when we first achieved civil flight. How we change after the transition is uncertain, but we know that flights will only get more comfortable. The list of changes goes on, but the essential aspect of electrification of aircraft propulsion is in the simplification of propulsion architectures whilst improving performance and minimising our environmental impact [1].

Fig. 1 shows that all-electric propulsion has the most simplistic architecture. It will also have a much simpler control system because an integrated computer can control the power inputs directly in the form of electricity, not liquid fuel, which is easier to predict and control. However,

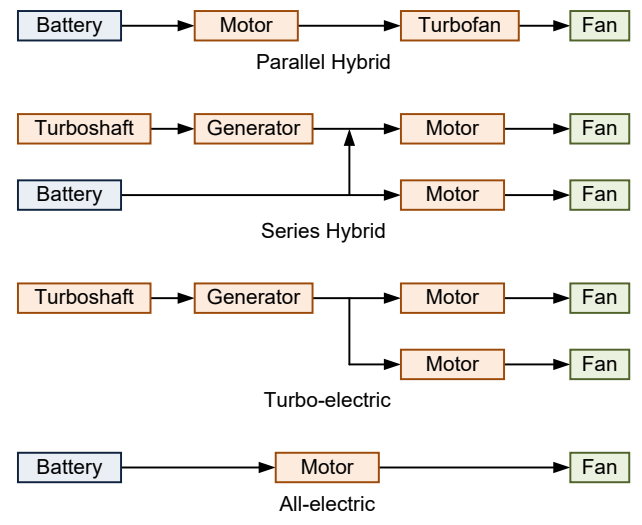

Fig. 1. Aircraft propulsion architectures [1].

Aircraft Electrical Propulsion (AEP) does not come without hurdles. Bolam et al. [3] highlighted that power generation and storage present the most significant challenge and many companies are investing heavily in this technology. Bolam et al. [3] also proposed using the rim-driven configuration, capable of multi-staging compared to its conventional counterpart, and later iterated that non-ferrous rim-driven rotors could have improved rotational stress distributions. Bolam et al. [4] concluded that electric motors could provide an ideal means to achieve AEP. Then, in a much later paper, reasoned that a rim-driven fan or compressor stages could operate independently, allowing the designers to implement counter-rotating stages; Fig. 2 is their demonstration of a static thrust comparison for small (200 $\mathrm{mm}$ diameter) single-stage and contra-rotating dualstage rim driven fan (RDF) [5].

\section{Velocity Diagram}

Velocity vector-diagrams provide an essential tool in the analysis of compressor and fan blade design as shown in Fig. 3, where $\Delta C_{w}$ is the change in fluid tangential velocity, $C_{b}$ is the blade tangential velocity, $C_{f}$ is the fluid axial velocity, $C_{a 1}$ is the leading edge absolute velocity, $C_{a 2}$ is the trailing edge absolute velocity, $C_{r 1}$ is the leading edge relative velocity, $C_{r 2}$ is the trailing edge relative velocity, $\alpha_{1}$ is the leading edge absolute velocity angle the rotor axis, $\alpha_{2}$ is the trailing edge absolute velocity angle the rotor axis, $\beta_{1}$ is the leading edge relative velocity angle the rotor axis, $\beta_{2}$ is the trailing edge relative velocity angle the rotor axis, $\Omega$ is the rotor angular velocity, and $r$ is the radial distance from the rotor axis.

$$
\Delta C_{w}=C_{f}\left(\tan \alpha_{2}-\tan \alpha_{1}\right)=C_{f}\left(\tan \beta_{1}-\tan \beta_{2}\right)
$$
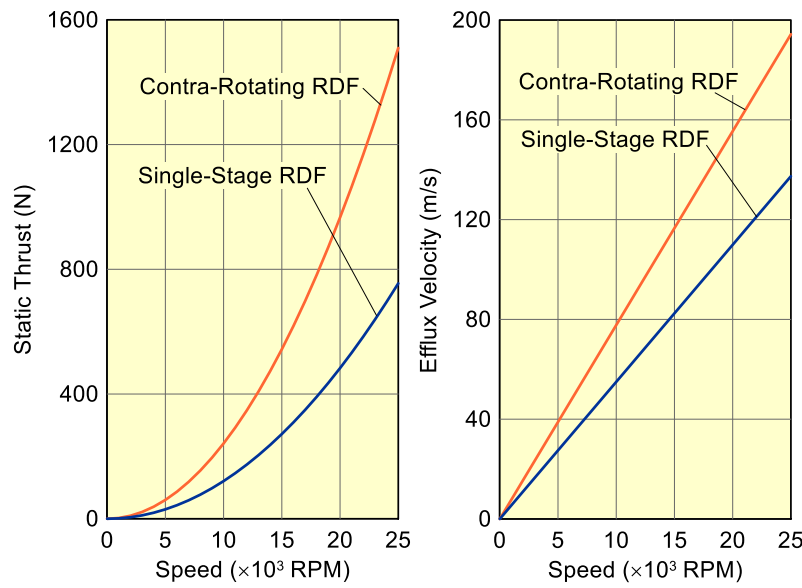

Fig. 2. Comparison of Single-Stage and Contra-Rotating RDF Thrust and Efflux Performances [5]. 

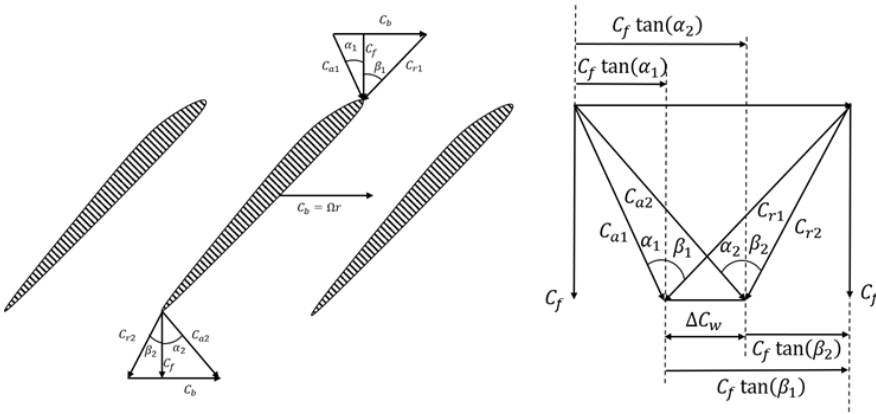

Fig. 3. Velocity triangle axial compressor or fan [6]

The air deflection angle $\varepsilon$ is

$$
\varepsilon=\beta_{2}-\beta_{1}
$$

The actual static enthalpy rise $\Delta h$ is

$$
\Delta h=C_{b} \Delta C_{w}
$$

The isentropic efficiency $\eta_{\text {isen }}$ is

$$
\eta_{i s e n}=\frac{\Delta h_{s}}{\Delta h}
$$

where $\Delta h_{s}$ is the isentropic enthalpy rise.

As demonstrated in Fig. 3 and (1), it is possible to approach the tangential velocity rise of the air using either relative velocity or absolute velocity values. Both approaches are valid, although for this paper we have chosen relative velocity as this value has plenty of applications. From (1) to (4), it is apparent that an increase in deflection could lead to higher isentropic efficiency.

\section{De Haller Number and Diffusion FaCtor}

The velocity diffusion of the airflow over compressor and fan blades result in a local pressure rise and the onset of boundary layer thickening. Which can eventually result in flow separation and blade stall. Although a degree of diffusion is intended over the blades it is important that it does not become excessive. The Diffusion Factor and the De Haller number offer effective methods of calculating the diffusion regime over a fan or compressor blade.

$$
\begin{aligned}
& \text { De Haller } \frac{C_{r 2}}{C_{r 1}} \geq 0.69 \\
& D F=1-\frac{C_{r 2}}{C_{r 1}}+\frac{\Delta C_{w}}{2 C_{r 1}} \times \frac{s}{c}
\end{aligned}
$$

where $D F$ is the diffusion factor, $s$ is the distance between two adjacent blades known as blade pitch, and $c$ is the blade chord length.

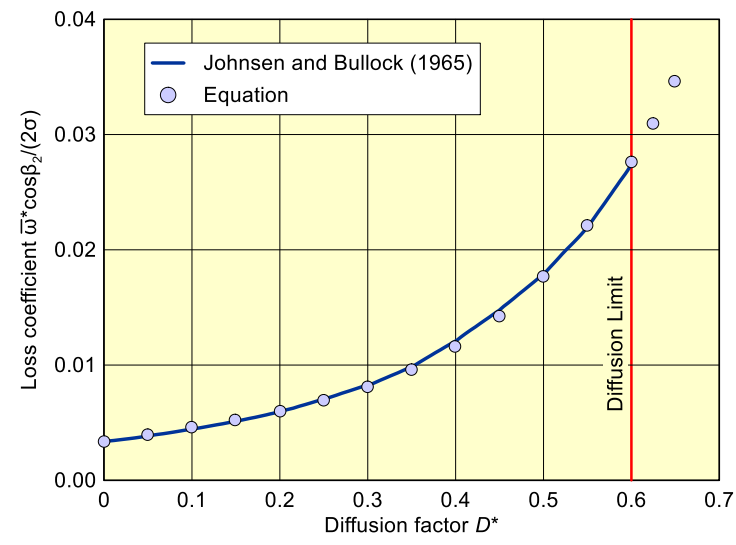

Fig. 4. Loss Coefficient as a function of $D^{*}$; data from [8].

$$
\frac{\bar{\omega}^{*} \cos \beta_{2}^{*}}{2 \sigma}=0.0035\left[1+3.5 D^{*}+37\left(D^{*}\right)^{4}\right]
$$

where $\bar{\omega}^{*}$ is the total pressure loss coefficient at design condition, $\beta_{2}^{*}$ is the relative velocity angle from the rotor axis at design condition, $\sigma$ is the cascade solidity, $D^{*}$ is the diffusion factor at design condition.

One must be aware of the relationship of increased deflection to diffusion. In the velocity diagram in Fig 3, it is apparent that an increase in deflection leads to higher diffusion; hence, there must be an upper limit where the diffusion would cause a high level of loss. In the early stage of design, the De Haller number, given by (5), can be used, but in the later stage of design, the more accurate diffusion factor, given by (6), which NACA developed, is found to be more reliable [7]. Aungier [8] demonstrated in Fig 4 that (7) follows the same results as the experimental results of Johnsen and Bullock [9].

\section{Work Coefficient (Stage Loading) AND FLOW COEFFICIENT}

The work and flow coefficient highly influence the compressor's and fan's performance. The stage loading is given by (8), and the flow coefficient is given by (9). One must decide which of these is the dominant factor when designing turbomachinery.

$$
\psi=\frac{\Delta h}{C_{b}^{2}}=\frac{\Delta C_{w}}{C_{b}}=\phi\left(\tan \alpha_{2}-\tan \alpha_{1}\right)=\phi\left(\tan \beta_{1}-\tan \beta_{2}\right)
$$

where $\psi$ is the work coefficient, and $\phi$ is the flow coefficient.

$$
\phi=\frac{C_{f}}{C_{b}}
$$

\section{Stall AND Surge}

An axial fan or compressor's stall characteristics, which depend upon the fan or compressor geometry, influence the acceptable operating range. The surge or stall points define the surge and stall limit lines, ultimately defining the operating range, as shown in Fig 5. Identifying the operating range is vital because the vibrations that can cause structural failure occurs under these conditions. The three main types of stalls are as follows:

1. A Rotating or Propagating stall is a large stall zone covering some of the blade passages. This type of stall is prevalent in all stall categories, and it can cause resonant blade vibration [10]. Cumpsty [11] and Graham and Guentert [10] further discuss that rotating stalls can be progressive or abrupt, on partial, or total span. Graham and Guentert [10] tabulated the characteristics of rotating stall with different velocity diagrams.

2. An Individual stall is a large flow separation region at the wake of a blade [10].

3. The Stall Flutter is the oscillation of blades at a high angle of attack associated with individual stalling [10].

In the early days of axial compressor and fan technologies, the term "surge" was used to describe when any form of flow fluctuation and noise came from the device. Even today, this had become an issue as many technologists have been using surge and stall as interchangeable terms, which, cannot be further from the truth. As an example, a rotating stall may cause surging, but surging cannot cause stalling. Cumpsty [11] and Huppert 


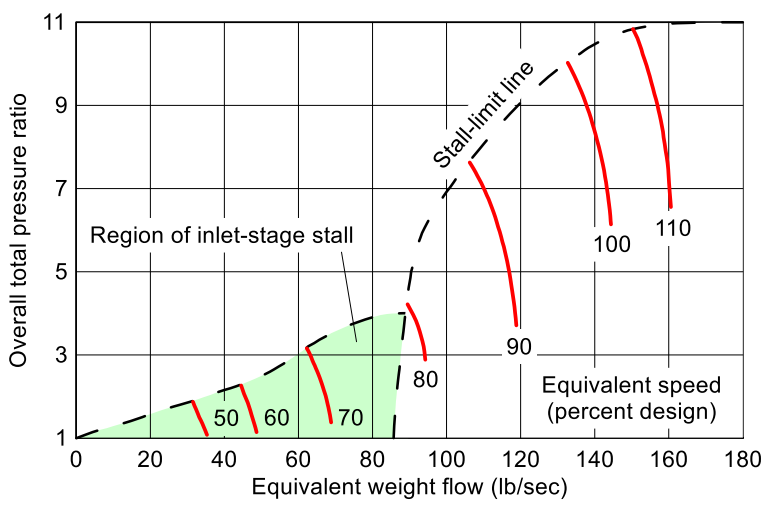

Fig. 5. Overall performance of a multistage compressor; data from [9].

[12] made a detailed description of the surge phenomenon. From Huppert [12], "Surge involves fluctuations in the net flow through the compressor whereas rotating stall consists of low-flow zones revolving about the compressor axis, but with a constant net or average flow through the compressor." Saravanamuttoo et al. [7] associate the surge with the sudden delivery pressure drop.

\section{EFFECTS of AsPect Ratio}

Howell [2] differentiated the aerodynamic losses into three categories: profile loss, secondary loss, and annulus loss, as shown in Fig 6. Shaalan [13] investigated the flow behaviour of two compressor cascades with different aspect ratios. At low speed the experiments found that the nature of the stall, at the endwall of the two cases, was significantly different with a substantial performance difference. The cascade with the higher aspect ratio had higher deflection at the mid-span before stalling but stalled first. Indicating it provided a limited range of none stalled operation with abrupt stall characteristics. In comparison, the cascade with the lower aspect ratio had a wider range of unstalled operation and a gradual stall progression but experienced a more severe flow separation with considerable flow contraction at the mid-span. Horlock [14] reviewed Shaalan's [13] report and found that the severe flow separation and bigger contraction deferred the stalling at the mid-span. Fligg [15] and Fahmi [16] are clear that the dominant effect of aspect ratio is the endwall stall behaviour. These pieces of literature are vital to compressor and fan designs however, new literature by To and Miller [17] shows that the behaviour of endwall stall is dependent on static pressure-rise coefficient and endwall geometry and independent of aspect ratio.

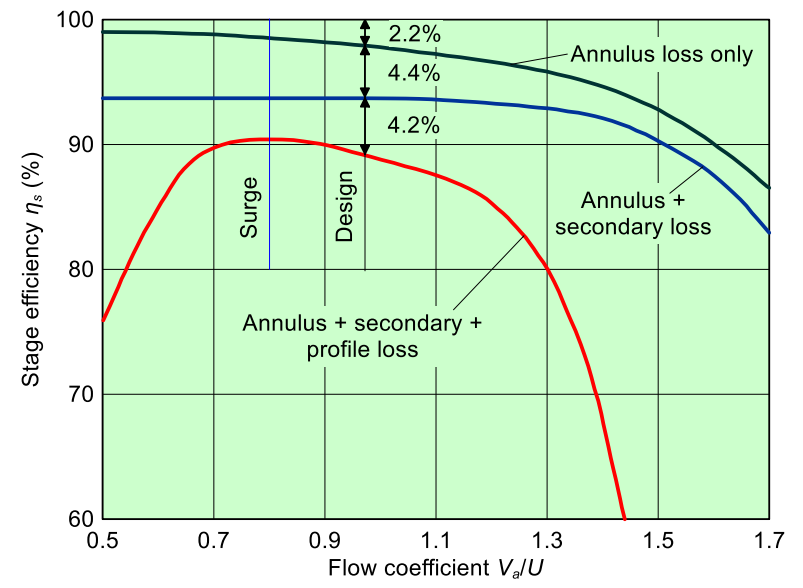

Fig. 6. General 3-dimensional flow effect in a compressor; data from [2]
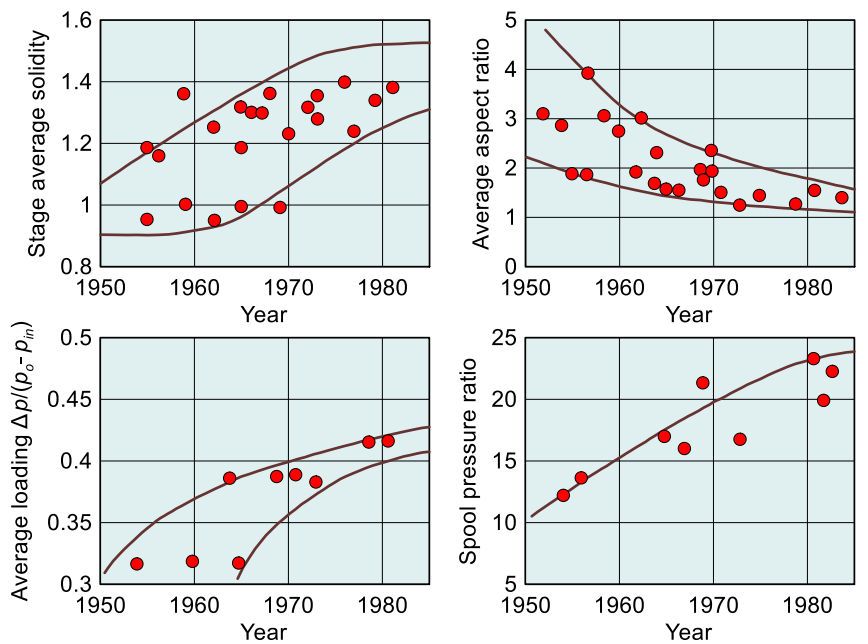

Fig. 7. The trend in compressor geometry with time; data from [11].

Fligg [15] mentioned that reducing weight through shortening of the chordlength sparked the investigation in aspect ratio and Horlock [14] came to the same conclusion. The quest for weight loss led to two groups of compressor and fan designers who would either lean towards lower aspect ratio or higher aspect ratio blades; both have their own merits. Higher aspect ratio blades yield higher isentropic efficiency by having higher deflection, as found by Shaalan [13] and shown in (1) to (4). Wisler [18] tabulated the changes of axial compressor blade geometry from the 1950s to the $1980 \mathrm{~s}$, and he found that the blade aspect ratio has been decreasing. Cumpsty [11] reasoned that lower aspect ratio blades are more effective at the endwall and better with vibration, favourable to designers and manufacturers. Wisler [18] and Wennerstrom [19] concluded that a higher aspect ratio blade predominantly has adverse effects on the compressor performance and mechanical structure.

Fig 8 and Fig 9 are two compressors from the late 1950s and early 1980s, respectively. Fig 9 has a lower aspect ratio but capable of a much higher pressure ratio of 23 , while Fig 8 has a higher aspect ratio and only capable of a pressure ratio of 12.5. The reason for this gap, however, is

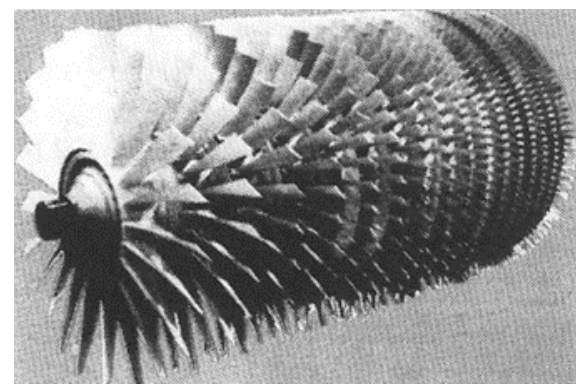

Fig. 8. CJ805/J79 rotor (late 1950s) [11].

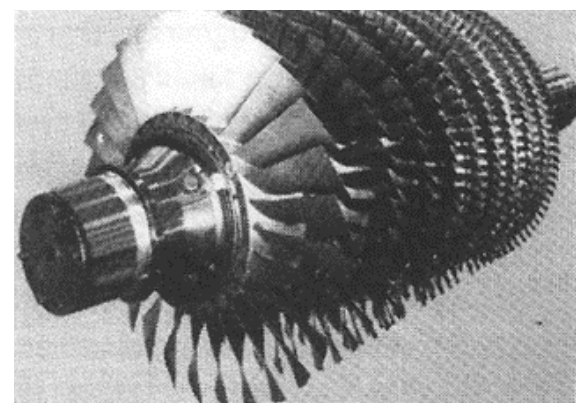

Fig. 9. $E^{3}$ rotor (early 1980 s) [11]. 


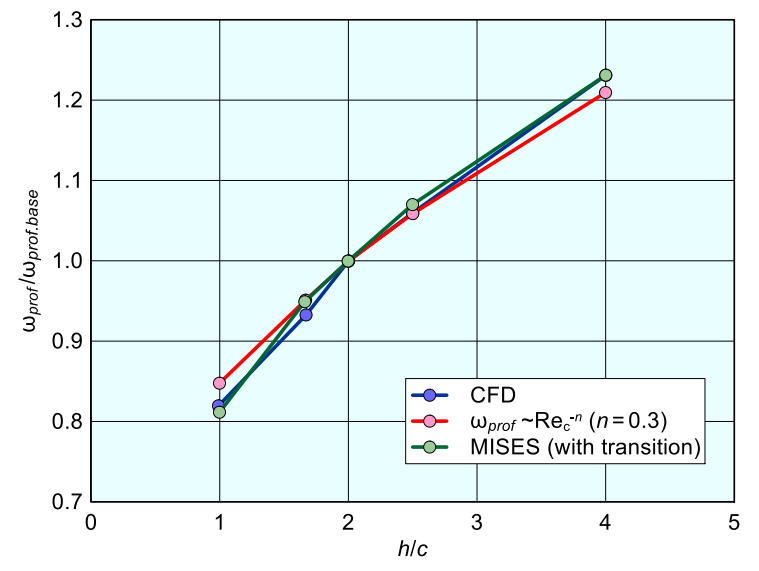

Fig. 10. Profile loss with increasing aspect ratio $\left(\omega_{\text {prof }}\right.$ is the profile loss coefficient ); data from [20].

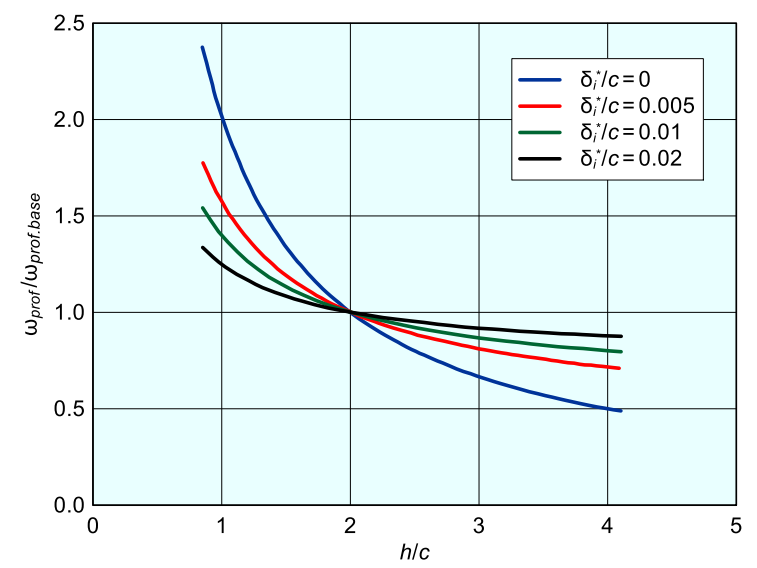

Fig. 11. Secondary loss with increasing aspect ratio $\left(\delta^{*}\right.$ is the distribution thickness); data from [20].

the technological developments made between the 1950s and 1980s. Nonetheless, it demonstrates that compressors with lower aspect ratio blades can outperform compressors with higher aspect ratio blades with the correct application.

Although Shaalan [13] demonstrated that the endwall behaviour differs with different aspect ratios, it did not answer how the change in aspect ratio affects a fan or compressor performance. For aspect ratios of 1, 2, and 4, Fligg [15] found no appreciable overall rotor efficiency change when measuring the rotor torque. While Fahmi [16] found that both rotors with the aspect ratio of 1 and 2 have the same work done, yet the rotor with an aspect ratio of 1 yields higher static pressure while operating at a slower speed than the rotor with an aspect ratio of 2; extrapolating from this data, the rotor with an aspect ratio of 1 would have higher isentropic efficiency. However, Britsch et al. [21] found an overall rotor efficiency increase with increased blade aspect ratio from 0.7 to 1.2 for the moderately loaded stage and 0.67 to 1.0 for the lightly loaded stage, but also found adiabatic efficiency reduction as blade aspect ratio increases from 0.7 to 1.2 for moderately loaded stage, and adiabatic efficiency increase as the blade aspect ratio increases from 0.67 to 1.0 for the lightly loaded stage. Comparing these results, Fligg's and Britsch's findings did not line up, and Fahmi's and Britsch's findings would only line up if Fahmi's rotors are moderately loaded, which has no mention in the paper.

Peter et al. [20] found that changing aspect ratio affects the profile and secondary loss differently. Fig 10 shows that profile loss increases with increasing aspect ratio and it is repeatable by different analytical means. Fig 11 shows that
TABle I. Review Key Findings

\begin{tabular}{|c|c|c|}
\hline Summary of Key Findings & $\begin{array}{l}\text { Blade Profile } \\
\text { Used in the } \\
\text { Experiment }\end{array}$ & Reference \\
\hline $\begin{array}{l}\text { The overall efficiency was measured from } \\
\text { torque and found no appreciable difference } \\
\text { in overall efficiency among the rotors. }\end{array}$ & Circular-Arc & Fligg [15] \\
\hline $\begin{array}{l}\text { No efficiency data was included in this } \\
\text { paper, but by extrapolating from the data } \\
\text { available in Fahmi's paper, it is concluded } \\
\text { that an increase in blade aspect ratio would } \\
\text { lead to adiabatic efficiency reduction. }\end{array}$ & $\mathrm{C} 4$ & $\begin{array}{c}\text { Fahmi } \\
{[16]}\end{array}$ \\
\hline $\begin{array}{l}\text { An increase in overall rotor efficiency for } \\
\text { both moderately and lightly loaded stages } \\
\text { with increasing blade aspect ratio but found } \\
\text { adiabatic efficiency reduction for moderately } \\
\text { loaded stage and increase in adiabatic } \\
\text { efficiency for the lightly loaded stage with } \\
\text { increasing blade aspect ratio. }\end{array}$ & $\begin{array}{c}\text { Double- } \\
\text { Circular-Arc }\end{array}$ & $\begin{array}{l}\text { Britsch } \\
\text { et al. [21] }\end{array}$ \\
\hline
\end{tabular}

secondary loss decreases with increasing aspect ratio but differs with different inlet displacement thickness. Peter et al. [20], then later concluded that the two main effects were the profile loss change due to Reynolds number and the change in secondary loss due to the variation in endwall boundary layer thickness.

Since the average optimum aspect ratio of modern blades often lies between 1 and 1.5, To and Miller [17] proposed using the "effective aspect ratio" for repeating stage compressors. This approach originated from the simplification of "linear repeating stages" by McKenzie [22], built upon the works of Smith [23]. As clearly stated by To and Miller [17], Fig 12 shows that the optimum aspect ratio is when the rate of increase of profile loss equals the rate of decrease of end-wall loss. The efficiency of axial compressors and fans depends on numerous variables, as shown in (10).

$$
\eta=f\left(\phi_{d}, \psi_{d}, \Lambda_{d}, M_{b}, D F, A R, \frac{t}{c}, \frac{s_{t c}}{c}, \mathrm{Re}_{c}, \text { config }\right)
$$

where $\phi_{d}$ is the designed flow coefficient, $\psi_{d}$ is the designed work coefficient, $\Lambda_{d}$ is the designed reaction, $M_{b}$ is the nondimensional blade speed, $A R$ is the blade aspect ratio, $t$ is the blade max thickness, $s_{t c}$ is the cantilever/shroud clearance, and $\operatorname{Re}_{c}$ is the Reynolds number based on the blade chordlength.

To and Miller [17] simplified their investigation to (11).

$$
\eta=f\left(A R, \frac{t}{c}, \frac{s_{t c}}{c}, \mathrm{Re}_{c}, \text { config }\right)
$$

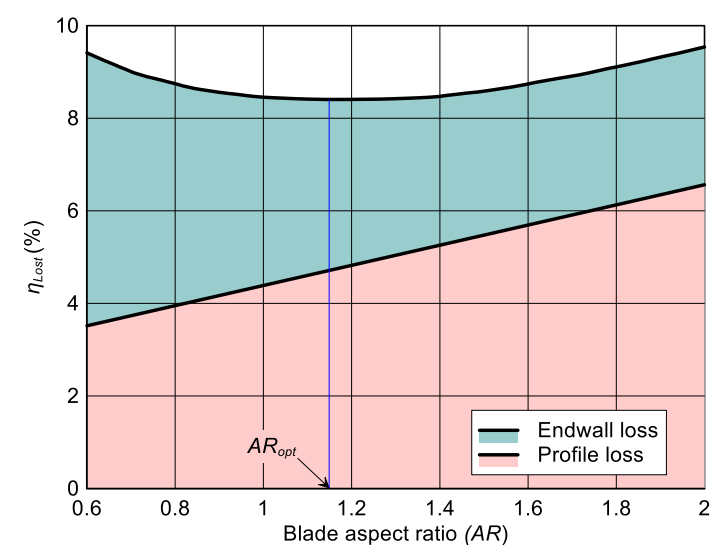

Fig. 12. Variation in lost efficiency with AR (fixed thickness and clearance); data from [17]. 
The approach of To and Miller [17] is elegant and intuitive; however, the scope of this approach only applies to repeating stages; hence, developing a similar approach for none repeating stages is of great interest.

\section{CONClusion}

Though there are various studies and investigations on how blade aspect ratio affects the overall performance of fuel-based and electric-powered fans or compressors, the authors had not found any literature on how the change in blade aspect ratio affects electric-powered rim-driven fans or compressors, nor how they perform with low aspect ratio blades. Therefore, one could only speculate that the transition to electric-powered rim-driven fans and compressors would not significantly affect the performance and fluid flow behaviour. Assuming this transition will not change the motion of the rotor, one can hypothesise that the change in aspect ratio should have a similar effect on electric-powered axial fans and compressors.

In this review it has been found that the studies relating fan blade aspect ratios and efficiencies are somewhat contradictory: Fligg [15] and Britsch et al. [21] both measured the overall rotor efficiency but their findings did not reach an agreement. Whilst Fahmi [16] and Britsch et al. [21] both measured adiabatic efficiency but would only reach an agreement if Fahmi's rotors are moderately loaded. Furthermore, as shown in Table I, Fligg, Fahmi, and Britsch et al. used different aerofoil profiles for their rotors. Therefore, Fligg's and Fahmi's results could have deviated from Britsch's results. Nonetheless, these contradictions highlight that we still do not fully understand the effects of blade aspect ratio on a compressor and fan. It is known that higher aspect ratio blades yield higher deflection, which gives higher efficiency based on equation 1 to 4 but also leads to a higher diffusion factor that can cause a higher loss coefficient. Indicating that there may be an aspect ratio value at which the deflection causes efficiency increase and loss coefficient reduction. Very much like To and Miller [17] proposed, this aspect ratio value might be the "optimum aspect ratio" for non-repeating stages.

Through the works of Shaalan [13], Fligg [15], Fahmi [16], Smith [23], Wisler [18], and Wennerstrom [19], it was found that lower aspect ratio blades have a wider stall margin, gradual stall progression, more structurally stable and less susceptible to vibration but suffer from severe stall conditions. This list of effects means that lower aspect ratio blades are better than higher aspect ratio blades in many areas. It is also proven by Fig 8 and Fig 9 that compressors with a lower aspect ratio can outperform a compressor with a higher aspect ratio with the correct implementation. However, these results are tested on hub-driven configuration; hence, this might not be the case for electricpowered rim-driven fans and compressors. Therefore, it was concluded that there is a significant body of research required in order to achieve multi-staging of electricpowered axial flow compressors and fans.

An area of great interest would be how a blade aspect ratio affects the overall performance and flow behaviour on a electric-powered rim-driven fans and compressors. We can speculate that this is different from a hub-driven fan or compressor with no tip clearance because the internal surface of the rim would be moving with the blades. The blade-rim junction could also generate interference vortices that can affect the performance, and one could hypothesise that a decrease in aspect ratio would increase the interference vortices as the length of the junction increases. Another area that one could explore is the relationship of the blending radius with interference vortices. Like a fairing of an aircraft where the wing joins the fuselage, the blending radius could affect the interference vortex generation.

\section{REFERENCES}

[1] R. Thomson, New Development in Aircraft Electrical Propulsion. London: Roland Berger, 2017.

[2] A. Howell, "Fluid dynamics of axial compressors," The Institution of Mechanical Engineers Proceedings: War Emergency Issues, vol. 153, no. 1, pp. 441-452, 1945.

[3] R.C. Bolam, Y. Vagapov, and A. Anuchin, "Review of electrically powered propulsion for aircraft," in Proc. 53rd Int. Universities Power Engineering Conf., Glasgow, UK, 4-7 Sept. 2018, pp. 1-6.

[4] R.C. Bolam, Y. Vagapov, and A. Anuchin, "A review of electrical motor topologies for aircraft propulsion," in Proc. 55th Int. Universities Power Engineering Conf., Turin, 1-4 Sept. 2020, pp. 1-6.

[5] R.C. Bolam, Y. Vagapov, J. Laughton, and A. Anuchin, "Optimum performance determination of single-stage and dual-stage (contrarotating) rim-driven fans for electrical aircraft," in Proc. XI Int. Conf. on Electrical Power Drive Systems, St. Petersburg, 2020, pp. 1-6.

[6] X. Huang, Thermo-fluids and Propulsion. Wrexham: Glyndwr University, 2017.

[7] H.I.H. Saravanamuttoo, G.F.C. Rogers, H. Cohen, and P.V. Straznicky, Gas Turbine Theory. Essex: Pearson, 2009.

[8] R. Aungier, Axial Flow Compressors: A Strategy for Aerodynamic Design and Analysis. New York: American Society of Mechanical Engineers, 2003.

[9] I.A. Johnsen, and R.O. Bullock, "Aerodynamic design of axial flow compressor," NASA, Cleveland, OH, USA, 1965.

[10] R.W. Graham, and E.C. Guentert, "Compressor stall and blade vibration," NASA, Washington, DC, USA, 1965.

[11] N. Cumspty, Compressor Aerodynamics, Essex: Longman, 1998.

[12] M. Huppert, "Compressor surge," NASA, Washington, DC, USA, 1965.

[13] M. Shaalan, A Wind-Tunnel Investigation of the Stalling Performance of Two Compressor Cascade of Differing Aspect Ratio at Low Speed. London: H.M.S.O., 1970.

[14] J. Horlock, "Some recent research in turbo-machinery," Proceedings of the Institution of Mechanical Engineers, vol. 182, no. 1, pp. 571594, 1967.

[15] J. Fligg, "Tests of a low-speed three-stage axial flow compressor at aspect ratios of one, two, and four," in Proc. 2nd Propulsion Joint Specialist Conf., Colorado Springs, CO, USA, 13-17 June 1966, Art. no 66-613.

[16] G. Fahmi, The Performance of Axial Flow Compressors of Differing Blade Aspect Ratio. London: H.M.S.O., 1971.

[17] Ho-On To, and R.J. Miller, "The effect of aspect ratio on compressor performance," Journal of Turbomachinery, vol. 141, no. 8, 2019.

[18] D. Wisler, "Aerodynamic effects of tip clearance, shrouds, leakage flow, casing treatment and trenching in compressor design," Von Karman Institute for Fluid Dynamics Lecture Series, 1985.

[19] A. Wennerstrom, "Low aspect ratio axial flow compressor: Why and what it means?" Journal of Turbomachinery, vol. 111, pp. 357-365, 1989.

[20] M. Peter, T. Schmidt, and P. Jeschke, "Influence of blade aspect ratio on axial compressor efficiency," Journal of the Global Power and Propulsion Society, vol. 3, no. 2019, p. 639-652, 2019.

[21] W.R. Britsch, W.M. Osborn, and M.R. Laessig, "Effects of diffusion factor, aspect ratio, and solidity on overall performance of 14 compressor middle stages," NASA, Cleveland, OH, USA, 1979.

[22] A. McKenzie, Axial Flow Fans and Compressors. Farnham: Ashgate Publishing, 1997.

[23] L.H. Smith, "Casing boundary layers in multistage axial flow compressors," in Proc. Brown Boveri Symp. on Flow Research on Blading, Baden, Switzerland, 10-11 March 1969, pp. 275-304. 